\title{
Evaluation of Avian Reovirus S1133 Vaccine Strain in Neonatal Broiler Chickens in Gastrointestinal Integrity and Performance in a Large-Scale Commercial Field Trial
}

\author{
Victor Manuel Petrone-Garcia 1,*(D), Joshua Gonzalez-Soto ${ }^{2}$, Raquel Lopez-Arellano ${ }^{3}$ (D), \\ Mariano Delgadillo-Gonzalez ${ }^{4}$, Victor M. Valdes-Narvaez ${ }^{5}$, Fernando Alba-Hurtado ${ }^{2}$, \\ Xochitl Hernandez-Velasco ${ }^{6}$, , Inkar Castellanos-Huerta ${ }^{1}$ and Guillermo Tellez-Isaias ${ }^{7}$ (iD)
}

1 Programa de Doctorado en Ciencias de la Salud y Producción Animal, Facultad de Estudios Superiores Cuautitlán, Universidad Nacional Autónoma de Mexico, Cuautitlán Izcalli 54714, Mexico; castellanos.inkar@gmail.com

2 Departamento de Ciencias Biológicas, Facultad de Estudios Superiores Cuautitlán, Universidad Nacional Autónoma de Mexico, Cuautitlán Izcalli 54714, Mexico; joshuagsotomvz@gmail.com (J.G.-S.); drfernandoalbafesc@gmail.com (F.A.-H.)

3 Laboratorio No 5: LEDEFAR, Unidad de Investigacion Multidisciplinaria, Facultad de Estudios

check for

updates

Citation: Petrone-Garcia, V.M.; Gonzalez-Soto, J.; Lopez-Arellano, R.; Delgadillo-Gonzalez, M.;

Valdes-Narvaez, V.M.; Alba-Hurtado, F.; Hernandez-Velasco, X.; Castellanos-Huerta, I.; Tellez-Isaias, G. Evaluation of Avian Reovirus S1133 Vaccine Strain in Neonatal Broiler Chickens in Gastrointestinal Integrity and Performance in a Large-Scale Commercial Field Trial. Vaccines 2021, 9, 817. https:/ / doi.org/10.3390/vaccines 9080817

Academic Editors: Caterina Lupini and Elena Catelli

Received: 6 June 2021

Accepted: 15 July 2021

Published: 23 July 2021

Publisher's Note: MDPI stays neutra with regard to jurisdictional claims in published maps and institutional affiliations.

Copyright: (c) 2021 by the authors. Licensee MDPI, Basel, Switzerland. This article is an open access article distributed under the terms and conditions of the Creative Commons Attribution (CC BY) license (https:/ / creativecommons.org/licenses/by/ $4.0 /)$. Superiores Cuautitlán, Universidad Nacional Autónoma de Mexico, Cuautitlán Izcalli 54714, Mexico; lopezar@unam.mx

4 Independent Poultry Zootechnical, Aguascalientes 20000, Mexico; degomariano@hotmail.com

5 Independent Poultry Nutritionist, Texcoco 56100, Mexico; valdesnv@gmail.com

6 Departamento de Medicina y Zootecnia de Aves, Facultad de Medicina Veterinaria y Zootecnia, UNAM, Coyoacan 04510, Mexico; xhernandezvelasco@gmail.com

7 Department of Poultry Science, University of Arkansas, Fayetteville, NC 72701, USA; gtellez@uark.edu

* Correspondence: petrone@unam.mx

\begin{abstract}
Avian reovirus (ARV) is the principal cause of several diseases. The vaccination of breeders allows for the control of viral arthritis and delivery of maternal-derived antibodies to the progeny. The vaccination of broiler chickens with ARV strain S1133 is used to prevent viral arthritis. However, the post-vaccination enteric effects have not been well-characterized. The purpose of this study was to evaluate the effect of vaccination with the S1133 strain on the weight gain and feed conversion of broiler chickens and to characterize the gastric, enteric, and pancreatic lesions that the strain could induce. A total of 672,000 chickens were divided into two groups: a group vaccinated with ARV strain S1133 (S1133ARV) and a control group (not vaccinated). Upon histological analysis, the vaccine group showed less proventricular glandular tissue and atrophy of the pancreas and duodenal villi, as well as having a lower average daily profit. The conclusion based on the results of this investigation is that neonatal vaccination with S1133ARV causes atrophy of the pancreatic acini, proventricular glands, and intestinal villi, leading to an increased diameter of the glandular lumen and atrophy of the enteric villous, as well as weight loss, in broiler chickens.
\end{abstract}

Keywords: reovirus S1133 vaccine; pancreatic and enteric histology; ELISA

\section{Introduction}

Avian reoviruses are part of the Reoviridae family in the genus Orthoreovirus. They are a nonenveloped virus composed of two concentric icosahedral capsids with an external diameter of 80-85 $\mathrm{nm}$ [1].

Member viruses have a broad host range, including metazoans, plants, protists, and fungi [2]. As in other species, the virus is abundant in poultry, and most reoviruses are innocuous [1-3]. The term "reovirus" is an acronym for "respiratory, enteric, orphan virus" since it was first isolated from the lungs and intestines in humans with no clinical signs [3]. In commercial poultry, pathogenic viruses cause significant economic losses due to arthritis and tenosynovitis in the gastrocnemius tendons [4]. Viral arthritis mainly 
affects meat-type chickens but has also been diagnosed in commercial layers [5]. Breeder flocks that develop viral arthritis during egg production may be characterized by lameness, increased mortality, decreased egg production, suboptimal hatchability/fertility, and vertical transmission of the virus to progeny [6]. Shedding of virulent reovirus vertically by a breeder flock may affect progeny and cause severe losses. Moreover, since avian reoviruses replicate in the gastrointestinal tract, they are also associated with other pathologies such as stunting malabsorption syndrome, hepatitis, gastroenteritis, myocarditis, and respiratory diseases $[3,7,8]$. Avian reoviruses possess group- and serotype-specific antigens, and neutralizing antibodies can be detected 7-10 days following infection.

Vaccination against reoviruses in broiler breeders is conducted with live apathogenic vaccines (strain 2177), modified vaccines (strain S1133), and inactivated vaccines produced with pathogenic reoviruses (strains S1133, 2408, SS412, and 1733). In some countries, homologous viruses from the poultry geographic area are also used $[1,3,4]$. The apathogenic live vaccine and inactivated vaccines are administered subcutaneously, while modified live vaccines are used in drinking water. Vaccination in broiler breeders is essential to protect them against viral arthritis. However, strong vaccination programs in breeders are also used to transfer passive immunity to protect their progeny against viral arthritis $[1,9,10]$. Neonate chickens are highly susceptible to pathogenic reovirus infection [11,12]. Hence, proper vaccination of broiler breeders is crucial [13,14]. Maternal antibodies can afford protection to 1-day-old chicks against natural and experimental infections, but the level of protection conferred by antibodies is related to serotype similarity, virus virulence, host age, and antibody titer [3]. Recovery from reovirus infection involves both B- and T-cell activity, but protection is predominantly B-cell-mediated (antibodies). Therefore, maternal immunity is essential for protection against viral arthritis [15]. The experimental suppression of T-cell-mediated immunity resulted in increased mortality in reovirus-infected birds, but the relative severity of tendon lesions was unaffected [16]. $\mathrm{CD} 8^{+} \mathrm{T}$ cells may play a major role in pathogenesis and/or reovirus clearance in the small intestine. In this process, maternal immunity does not play an important role [17].

The S1133 avian reovirus strain (S1133ARV) is the most widely used for vaccination, and it has been effective against viral arthritis in most parts of the world [1]. However, as far as we are aware, no evidence of the clinical expectation has been reported on using the live modified S1133ARV strain in neonate broiler chickens under commercial conditions. Hence, the purpose of this study was to evaluate the effect of S1133ARV on the weight gain and feed conversion of broiler chickens following vaccination with this strain, in addition to characterizing the gastric, enteric, and pancreatic lesions induced in response 1-day-old broiler chickens in a large-scale commercial field trial in Mexico.

\section{Materials and Methods}

\subsection{Application of the Avian Reovirus S1133 Strain Vaccine in Broiler Chickens under Commercial Conditions}

\subsubsection{Location and Facilities of the Large-Scale Commercial Field Trial}

This study was conducted at the regional complex for one slaughterhouse from an integrated poultry producer located in Aguascalientes, Mexico, with a clinical history of previous flocks of diarrhea with undigested feed with orange mucus, twisted pancreas, and a deficit of $4 \mathrm{~g} \cdot \mathrm{day}^{-1}$ of average daily gain, without arthritis or tenosynovitis. Twenty-four chicken houses with a capacity of 28,000 female broiler chickens were selected ( $n=672,000$ total chickens). Twelve houses were randomly selected, and chickens were vaccinated at 1-day-old using a spray cabinet with the avian reovirus S1133 strain, whereas the other twelve houses served as the nonvaccinated control group. Chickens were raised under normal production conditions and fed a four-phase commercial basal diet [18] (Table S1, Supplementary Materials). Evaluation of production parameters was done at the end of the grow-out cycle (38 days of age). Chickens were housed in a conventional farm with natural ventilation featuring an age-appropriate environment and kept under ambient conditions using the equipment recommended by the Ross broiler management 
handbook [19]. Evaluated parameters included the age of the birds at processing, average daily gain (ADG), feed conversion rate (FCR), livability (LI), and production efficiency factor (PEF).

\subsubsection{Source of Animals}

Female broiler chickens were hatched at the commercial hatcheries of a Mexican poultry company in Aguascalientes, Mexico. The ROSS ${ }^{\circledR} 308$ chickens (Aviagen ${ }^{\circledR}$, Huntsville, AL, USA) came from imported embryos (Keith Smith Farms ${ }^{\circledR}$, Hot Spring, AR, USA). The reovirus vaccination program for broiler breeders with an active virus was performed, as described, according to age: on day 0 with the 2177 strain $\left(2177^{\circledR}\right.$, Merck Sharp and Dohme Corp, Kenilworth, NJ, USA); at 2, 4, and 6 weeks with the inactivated virus strain S1133 (Enterovax ${ }^{\circledR}$, Merck Sharp and Dohme Corp, Kenilworth, NJ, USA). Vaccination with the inactivated virus was performed at 12 weeks using the inactive S1133, 2408, and SS412 strains (Maximune ${ }^{\circledR} 8$, Ceva, Libourne, France), as well as the autogenous strain (custom KV: 9802. Elanco, Greenfield, IN, USA), and at 18 weeks with the S1133 (AviPro ${ }^{\circledR} 106$ REO or KV: 7805, Elanco, Greenfield, IN, USA), and 1733 strains (AviPro ${ }^{\circledR} 106$ REO or KV: 7805, Elanco, Greenfield, IN, USA), as well as the autogenous strain (custom KV: 9802, Elanco, Greenfield, IN, USA).

\subsubsection{Avian Reovirus $S 1133$ Vaccine}

The avian reovirus strain S1133 included in the live modified virus vaccine cloned in tissue culture (Enterovax ${ }^{\circledR}$, Merck Sharp and Dohme Corp, Kenilworth, NJ, USA) was used as the challenge virus with a titer of $10^{6.5}$ median tissue culture infectious dose $\left(\mathrm{TCID}_{50}\right) / \mathrm{mL}$ according to the manufacturer's recommendation. Chickens in the vaccinated group received a full dosage of avian reovirus S1133 strain [20] at 1-day-old using a spray cabinet (Spra-Vac II ${ }^{\circledR}$, Boehringer Ingelheim Vetmedica ${ }^{\circledR}$, Guadalajara, Mexico).

\subsection{Performance Variables}

The performance variables were calculated as described in this section. The gain weight of the flock (GWF) was measured in kg at slaughterhouse reception divided by the initial number of chicks (INC), excluding mortalities at chick reception. The gain weight of the chickens (GWC) was calculated from the GWF divided by the INC. The ADG (g.day ${ }^{-1}$ ) was calculated from the GWC divided by the INC. Mortality was calculated based on chickens received at slaughterhouse reception from the IAC. Livability (LI) was calculated by subtracting the mortality from 100 . The feed intake of the flock (FIF) was determined as the difference between the total amount of feed offered and the number of refusals. The feed conversion ratio (FCR) was calculated by dividing FIF with GWF. The production efficiency factor (PEF) was calculated using the following equation:

$$
\mathrm{PEF}=\frac{\mathrm{LI}(\%) \times \mathrm{GWC}(\mathrm{kg})}{\text { Age }(\text { days }) \times \mathrm{FCR}} \times 100 .
$$

\section{Cost-Benefit Calculation of Vaccination against Avian Reovirus}

A cost matrix was built with variable feed intake $\cdot$ chick $^{-1}$ by average feed cost (462.38 USD), according to the feed program and constant other costs (0.82 USD chick $^{-1}$ ), estimated using the chicken production cost of the Mexican Poultry Federation (UNA) [21] (Table S2, Supplementary Materials). The avian reovirus group included an additional cost of 0.0102 USD. chick ${ }^{-1}$. Chick income was obtained in terms of live body weight (kg) by actual price per kg (1.60 USD), as a function of livability. Profiles were calculated as the difference between chicken income and cost [22].

\subsection{Sample Collection and Processing}

Figure 1 shows the methodology flow chart. At $0,7,14,21,28$, and 35 days of age, 10 chickens from each house were blended $(n=120)$ from each group. The blood serum 
was placed in refrigeration $\left(2^{\circ} \mathrm{C}\right)$. At 14 days of age, one chicken from each chicken house was randomly selected $(n=12)$ from each group, euthanized by cervical dislocation, and necropsied. Samples of each chicken were taken from the middle parts of the proventriculus $(\mathrm{PV})$, pancreas (PA), proximal duodenal branch (PD), and distal duodenal branch (DD), as well as $3 \mathrm{~cm}$ caudally to Meckel's diverticulum in the distal jejunum (DJ) (Figure 2a). The samples were fixed immediately by immersion in 10\% neutral buffered formalin. Tissues were then processed and embedded in paraffin using routine histological techniques.

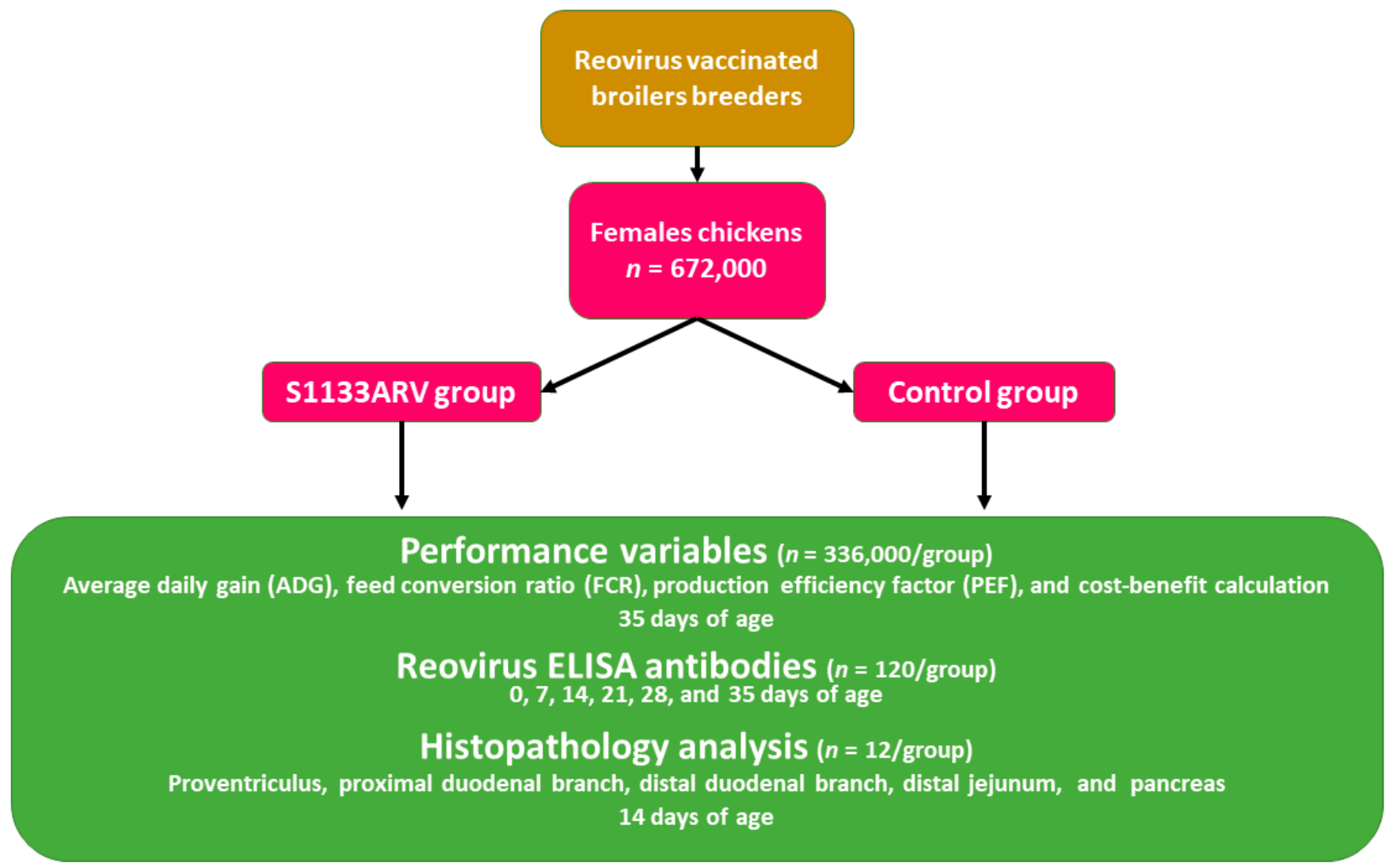

Figure 1. Twenty-four chicken houses with a capacity of 28,000 female broiler chickens were selected from a commercial company ( $n=672,000$ total chickens). Twelve houses were randomly selected, and chickens were vaccinated at 1-day-old using a spray cabinet with the avian reovirus S1133 strain, whereas the other 12 houses served as the nonvaccinated control group. The variables evaluated were productive performance, reovirus ELISA antibodies, and histopathology analysis. 


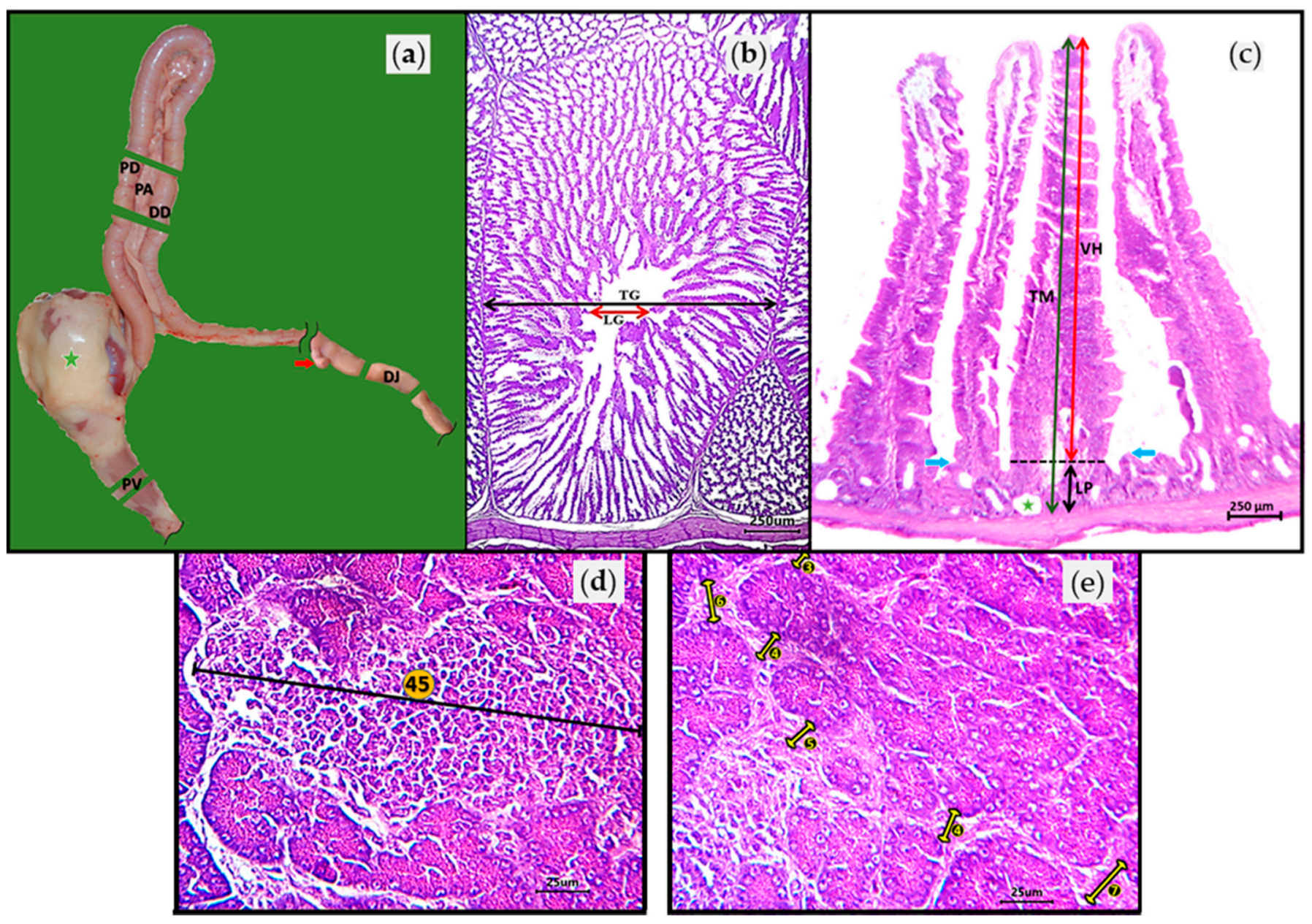

Figure 2. (a) Sites where histopathological samples were taken from each chicken from the middle parts of the proventriculus (PV), pancreas (PA), proximal duodenal branch (PD), and distal duodenal branch (DD), as well as $3 \mathrm{~cm}$ caudally to Meckel's diverticulum (red arrow) in the distal jejunum (DJ). Green star = ventricle (gizzard); (b) PV consisted of measuring the transverse diameter of the total (TG and black arrow) and luminal (LG and red arrow) diameter of the proventricular gland; (c) Intestinal evaluation involved measuring the total thickness (TM, green arrow) and lamina propria (LP, black arrow) of the mucosa, as well as the villous height (VH, red arrow). The segmented line indicates the boundary between LP and VH. The blue arrows indicate the upper pole of the enteric glands that comprise the lintel of the LP. The green star indicates an enteric gland cyst; (d) Pancreas histopathologic analysis showing the lymphocyte cluster. The largest cross-diameter (black line) of the lymphocyte clusters was used to quantify the number of lymphocyte cell layers (number in orange circle); (e) Pancreas parenchyma. The acinar fibrosis/atrophy score was based on the number of fibroblast layers (number in black circle) embedded in bands separating the pancreas acini.

\subsection{ELISA for Assessment of Reovirus Antibodies}

The obtained serum samples were analyzed for antibodies against reovirus using commercially available enzyme-linked immunosorbent assay tests (Reo ELISA CK100 ${ }^{\circledR}$, BioCheck ${ }^{\circledR}$ UK LTD, Ascot, UK). The ELISA commercial test is widely used for assessing reovirus antibody levels on a flock basis. The test is efficient for the detection of antibodies to avian reovirus in Gallus gallus. The ELISA method was developed using whole virus antigen, as well as recombinant $\sigma \mathrm{C}$ and $\sigma \mathrm{B}$; thus, the test disallows the differentiation of infected from vaccinated chicks [23].

\subsection{Histopathology}

Paraffin-embedded tissues were sectioned, mounted, and stained using hematoxylin and eosin (H\&E) and examined for lesions; tissues were evaluated by photon microscopy 
using the AmScope ${ }^{\circledR} 3.7$ (Irvine, CA, USA) image analysis program. Each tissue was also assigned a lesion severity score. The proventriculus evaluation consisted of measuring the transverse diameter of the total diameter (TG) and the luminal diameter (LG) of the proventricular gland (Figure $2 \mathrm{~b}$ ). Lymphoid nodules contained in the glandular zone of the proventricular mucosa were also counted. The intestinal evaluation considered the PD, DD, and DJ. From the three intestinal zones, the total thickness (TM) and the lamina propria (LP) of the mucosa were measured, in addition to the villous height (VH) (Figure 2c). Cysts and lymphoid clusters contained in the glandular zone of the intestinal mucosa were also counted. Pancreas analysis consisted of obtaining the percentage tissue degeneration and counting the necrotic foci and lymphoid clusters; the fibrosis/acinar atrophy score was also calculated. The lymphoid infiltrate was evaluated using a digital microscope camera with a field of view (FOV) of $3.4 \mathrm{~mm}^{2}$ using a $5 \times$ objective lens. The largest cross-diameter of the lymphocyte clusters was used to quantify the number of lymphocyte cell layers (Figure 2d). The acinar fibrosis/atrophy score was based on the number of fibroblast layers embedded in bands separating the PA acini (Table 1). The acinar fibrosis/atrophy score was evaluated with a FOV of $0.87 \mathrm{~mm}^{2}$ and a $10 \times$ objective lens (Figure 2e). The acinar fibrosis/atrophy was obtained from the total of 60 scores calculated (five FOVs for 12 tissue cuts). The number of layers was multiplied by the number of clusters, and the average was obtained from the total of 60 scores calculated (five FOVs for 12 tissue cuts).

Table 1. Pancreas acinar fibrosis/atrophy score of the broilers vaccinated with the avian reovirus S1133 strain.

\begin{tabular}{|c|c|c|c|}
\hline \multirow[b]{2}{*}{ Score } & \multicolumn{3}{|c|}{$\begin{array}{c}\text { Percentage (\%) of Fibrous Tissue Bands Separating the Pancreatic Acini According to the Number of } \\
\text { Fibroblast Layers* }\end{array}$} \\
\hline & 1 to 2 Layers & 3 to 5 Layers & More than 5 Layers \\
\hline 0 & 0 & & \\
\hline 0.5 & $1-5$ & & \\
\hline 1 & $6-15$ & & \\
\hline 1.5 & $16-20$ & $1-5$ & \\
\hline 2 & $21-35$ & $6-15$ & \\
\hline 3 & $36-50$ & $16-20$ & $1-5$ \\
\hline 4 & $51-70$ & $21-35$ & $6-15$ \\
\hline 5 & $71-85$ & $36-50$ & $16-20$ \\
\hline 6 & $86-100$ & $51-70$ & $21-35$ \\
\hline 7 & & $71-85$ & $36-50$ \\
\hline 8 & & $86-100$ & $51-70$ \\
\hline 9 & & & $71-85$ \\
\hline 10 & & & $86-100$ \\
\hline
\end{tabular}

* The largest number of fibroblast layers observed in the digital microscope camera's field of view in a single column.

\subsection{Data and Statistical Analysis}

The fibrosis/atrophy PA score was analyzed using the Mann-Whitney U test. The remaining data confirmed normal distribution (Shapiro-Wilk test) and homoscedasticity (Levene test). Consequently, the data were subjected to a parametric test (one-tailed Student's $t$-test). Prior to statistical analysis, the percentage mortality, L/TG, LP/V, and degeneration PA were subjected to an arcsine square root transformation. The statistical significance was set at $p<0.05$.

\section{Results}

\subsection{Performance Variables}

The results of the performance variables of the female broiler chickens vaccinated with the avian reovirus S1133 strain are summarized in Table 2. Significant reductions $(p<0.05)$ in average daily gain and production efficiency factor, as well as an increase in FCR, were observed in chickens that received the avian reovirus vaccine when compared with nonvaccinated control chickens (Table 2). 
Table 2. Performance variables of female broiler chickens vaccinated with the avian reovirus S1133 strain.

\begin{tabular}{|c|c|c|c|c|}
\hline Broiler Groups & $\operatorname{ADG}\left(\mathrm{g} \cdot \mathrm{day}^{-1}\right)$ & FCR & LI (\%) & PEF \\
\hline S1133ARV group & $43.46 \pm 0.53^{b}$ & $1.641 \pm 0.009^{\mathrm{a}}$ & $95.16 \pm 0.35$ & $253.64 \pm 3.17^{b}$ \\
\hline Control group & $44.82 \pm 0.46^{\mathrm{a}}$ & $1.592 \pm 0.015^{b}$ & $94.60 \pm 0.54$ & $266.74 \pm 4.68^{a}$ \\
\hline$p$-Value & $p=0.029$ & $p=0.018$ & $p=0.209$ & $p=0.010$ \\
\hline
\end{tabular}

ADG = average daily gain, FCR = feed conversion ratio, $\mathrm{LI}=$ livability, PEF = production efficiency factor. Data are expressed as the mean \pm standard error. ${ }^{\mathrm{a}, \mathrm{b}}$ Different superscript letters within columns indicate a significant difference at $p<0.05$.

\section{Cost-Benefit Calculation}

The two groups presented the same cost of production $(p=0.4789)$. However, the S1133ARV group presented lower income and profits $(p=0.0229$ and $p=0.0335)$ than the control group (Table 3).

Table 3. Cost-benefit analysis of using the S1133ARV vaccine strain in female broilers.

\begin{tabular}{cccc}
\hline Broiler Groups & Income (1.60 USD $\cdot \mathbf{k g}^{-\mathbf{1}}$ ) & Cost & Profit \\
\hline S1133ARV group & $2.516 \pm 0.108^{\mathrm{b}}$ & $2.076 \pm 0.051$ & $0.440 \pm 0.116^{\mathrm{b}}$ \\
Control group & $2.581 \pm 0.073^{\mathrm{a}}$ & $2.075 \pm 0.045$ & $0.506 \pm 0.062^{\mathrm{a}}$ \\
$p$-Value & $p=0.0229$ & $p=0.4789$ & $p=0.0335$ \\
\hline
\end{tabular}

The amounts are indicated in USD. Data are expressed as the mean \pm standard deviation. ${ }^{\mathrm{a}, \mathrm{b}}$ Different superscript letters within columns indicate a significant difference at $p<0.05$.

\subsection{Histopathology}

Table 4 shows histological measurements of the proventricular gland from broilers vaccinated with the S1133 reovirus strain. Both groups had the same TG of the PV ( $p=0.724)$, whereas the LG of the proventricular glands of the S1133ARV-vaccinated broilers was higher than that of the control broilers $(p=0.017)$.

Table 4. Histological measurements of the proventricular gland from broiler chickens vaccinated with the $\mathrm{S} 1133$ reovirus strain.

\begin{tabular}{ccc}
\hline Broiler Groups & $\begin{array}{c}\text { TG } \\
(\mathbf{m m})\end{array}$ & $\begin{array}{c}\text { LG } \\
(\mathbf{m m})\end{array}$ \\
\hline S1133ARV group & $1.442 \pm 0.285$ & $0.424 \pm 0.193^{\mathrm{a}}$ \\
Control group & $1.144 \pm 0.254$ & $0.240 \pm 0.114^{\mathrm{b}}$ \\
$p$-Value & $p=0.724$ & $p=0.017$
\end{tabular}

TG = transverse diameter of the gland, $\mathrm{LG}=$ transverse diameter of the lumen of the gland. Data are expressed as the mean \pm standard deviation. ${ }^{a, b}$ Different superscript letters within columns indicate a significant difference at $p<0.05$.

The histological measurements of the enteric mucosa from female broilers vaccinated with the reovirus strain S1133 are summarized in Table 5. The VH values from the PD of the control broilers were higher than those of the S1133ARV-vaccinated broilers $(p=0.00005)$. However, both groups had the same VH and TM of the DD and DJ ( $p=0.075$ and $p=0.066$ ). The LP of the PD and the DD of the S1133ARV-vaccinated broilers were higher $(p=0.00005$ and $p=0.015)$ than those of the control broilers. However, both groups had the same LP of the DJ ( $p=0.365)$. Both groups had the same TM of the PD $(p=0.242)$, the DD $(p=0.189)$, and the DJ $(p=0.123)$. 
Table 5. Histological measurements of the enteric mucosa from broiler chickens vaccinated with the avian reovirus $\mathrm{S} 1133$ strain.

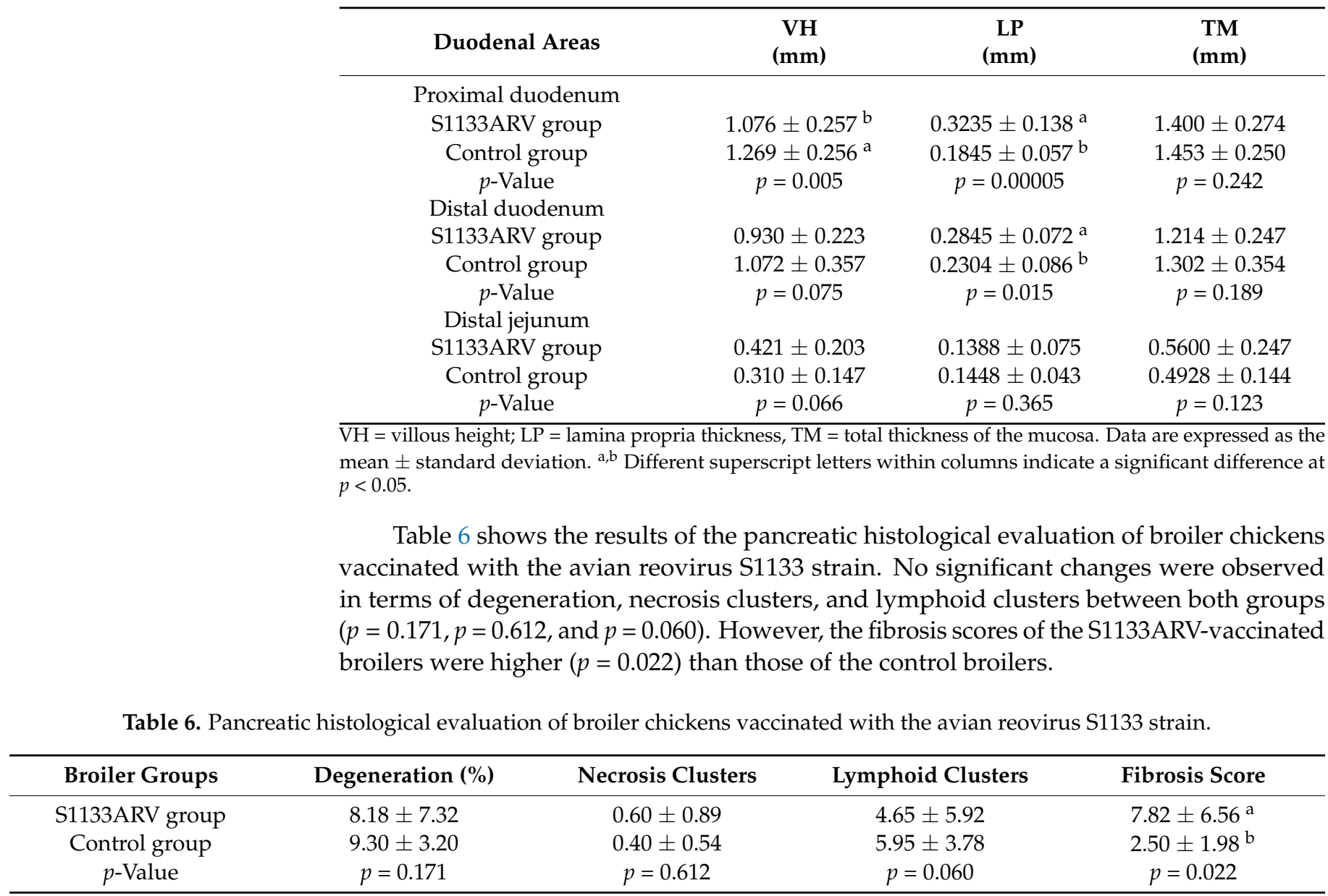

Table 6. Pancreatic histological evaluation of broiler chickens vaccinated with the avian reovirus S1133 strain.

Data are expressed as the mean \pm standard deviation. ${ }^{a, b}$ Different superscript letters within columns indicate a significant difference at $p<0.05$.

\subsection{Antibody Titers}

The results of the antibody titers from broiler chickens vaccinated with the avian reovirus S1133 strain are shown in Figure 3. Chickens in both groups revealed a high maternal antibody titer against the avian reovirus S1133 strain, which is consistent with the vigorous vaccination program of broiler breeders against reoviruses. In both groups, maternal antibody titers showed a progressive reduction on days 7, 14, and 21 of evaluation. Interestingly, on days 28 and 35 , the antibody titers in both groups were increased. However, no differences $(p>0.05)$ in antibody titers were found between the two groups across all weeks of evaluation (Figure 3). 


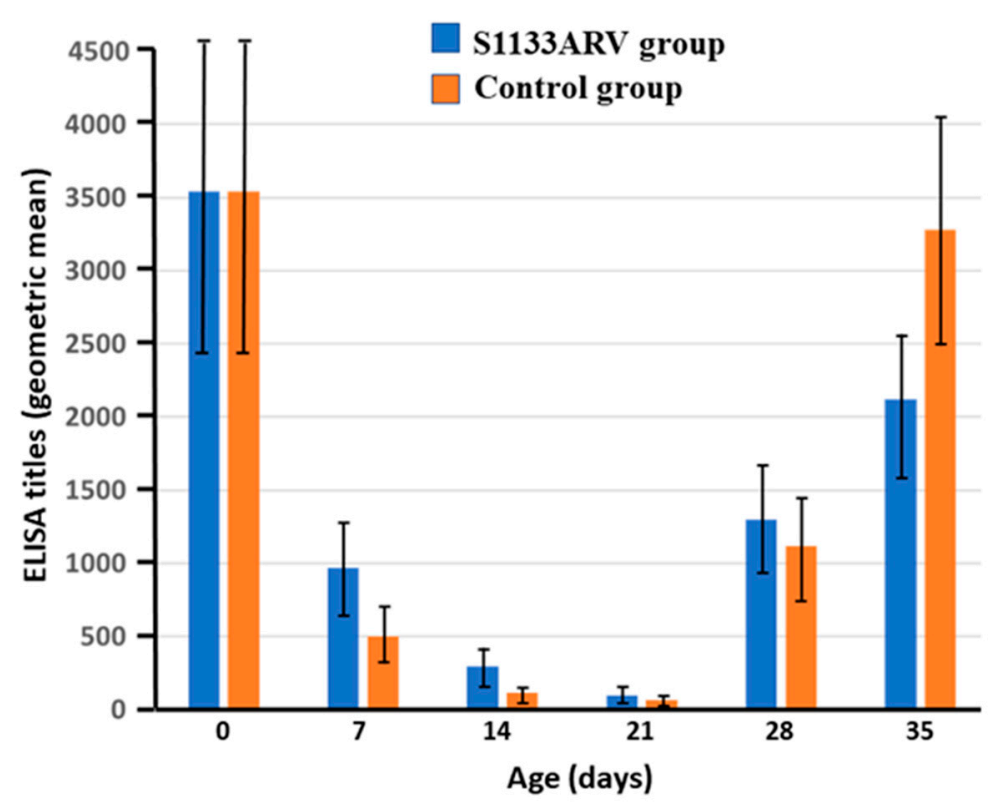

Figure 3. Antibody titers from broilers vaccinated with the avian reovirus S1133 strain $(p>0.05)$.

\section{Discussion}

The results of the present study indicate that vaccination of neonatal broiler chickens with the avian reovirus S1133 strain has a negative economic and productive impact since replication of the virus induces pathological alterations in the gastrointestinal tract. The use of the vaccine was not justified in the cost-benefit analysis.

The reduction in performance was associated with histopathologic and morphometric changes in the proventricular gland, duodenum, and pancreas of female broiler chickens that were commercially processed at 38 days of life. These findings agree with previous researchers who reported that avian reovirus isolated from intestinal contents of broiler chickens with malabsorption syndrome produced a transient but significant depression in body weight gain when inoculated orally into 1-day-old chicks [24]. In addition, Jones and Georgiou found that resistance to reovirus is age-related because, although reoviruses can infect older birds, the resulting disease is generally less severe, and the incubation period is longer [6].

The decline in the performance of vaccinated broilers can be explained by histological findings. The luminal diameter of the proventricular gland was significantly larger in the vaccinated group. This increase in lumen was due to a reduction in glandular tissue, which caused the ratio of the lumen over the total glandular diameter radius to increase. As is known, glandular tissues produce hydrochloric acid and pepsinogen, which are essential for the digestion of proteins [25].

In the duodenal villi of the vaccinated group, there was a decrease in villus height and an increase in lamina propria such that the ratio of the lamina propria thickness over the total thickness of the mucosa radius increased. Apoptosis is the process via which reoviruses cause epithelial atrophy of the proventricular glands and the epithelium at the tip of the villi [26,27]. This phenomenon may explain the absence of an evident inflammatory process in the tissues observed in this work [28]. These duodenal changes induce a decrease in nutrients, especially in proteins. The highest absorption of proteins in the duodenum occurs in its proximal part, which is the most strongly affected by the vaccine. While the effect of the vaccine virus on enteric villi was lost in the distal jejunum, the absorption of nutrients was lower [25,29].

The pancreas of vaccinated broilers exhibited moderate fibrosis, but this fibrosis was higher in vaccinated chickens compared with nonvaccinated control chickens. An increase in the amount and density of the interstitial connective tissues with compression atrophy of 
the acini characterizes the chronic phases of inflammation in the pancreas [30-32]. Typically, bands of mature fibrous tissue separate small lobules of acinar tissues [33]. Pancreatic fibrosis is attributed to selenium deficiency in stunted broilers. One of the limitations of the present study is that the concentration of selenium was not measured. However, a reduction in nutrient absorption is associated with selenium deficiency [34]. It is suggested that the normally low activities of selenium-dependent glutathione peroxidase (SeGSHpx) in the pancreas may predispose that organ to atrophy due to oxidative stress under conditions of nutritional selenium deficiency, resulting in further depletion of SeGSHpx [25]. Pancreatic atrophy seems to be dependent on selenium concentration. In the present study, the pancreatic atrophy was moderate, whereas, in the works of Whitacre et al. [35] and $\mathrm{Xu}$ et al. [31], the deficiency and atrophy were severe.

The results of the ELISA revealed a high maternal antibody titer, which is consistent with the vigorous vaccination program of broiler breeders against reoviruses. However, the maternal antibodies did not prevent infection of the live modified avian reovirus S1133 strain in the gastroenteric epithelium. Hence, the replication of the S1133 strain caused damage to the proventricular glands and enterocytes. In the present study, maternal antibodies decreased at 3 weeks of age in both groups. Interestingly, an increase in antibody titers was observed in both groups, presumably, due to a wild reovirus challenge that was not controlled by vaccination, as previously reported by Zhong et al. [13]. Reoviruses can be isolated from healthy birds, and serum antibodies are often found in both affected and healthy birds [3]. Another limitation of the present field trial study is the lack of isolation and characterization of the wild strain(s) responsible for inducing an immune response in nonvaccinated control chickens. However, in the present study, performance parameters of nonvaccinated control chickens were not affected, even though they showed antibody titers against avian reovirus. The ELISA commercial kit used to evaluate antibody titers (Reo ELISA CK100 ${ }^{\circledR}$, BioCheck $^{\circledR}$ ) allows for the detection of serum antibodies against all serotypes of avian reovirus in both vaccinated and nonvaccinated flocks; hence, it can be used for screening for field infections, as well as for monitoring vaccination success in poultry. In summary, while the large sample size and per-house randomization schema provide conclusive data regarding the effect of the reovirus S1133 challenge in the present study, limitations to the generalizability of these results compared with other commercial facilities receive short shrift. Further studies to evaluate the use of the reovirus S1133 strain in neonate commercial chickens under different breeder vaccination stratagems that may affect maternal antibody levels or under different background prevalence of ARV infection should be investigated.

\section{Conclusions}

Strong broiler breeder vaccination programs with the avian reovirus S1133 strain are designed to prevent viral arthritis in breeders and the progeny through passive immunity. Since the virus replicates in the gastrointestinal tissue, regardless of the maternal antibodies, the results of the present study suggest that neonatal vaccination in broiler chickens with the live avian reovirus S1133 strain should be avoided, as it leads to a disruption of gastrointestinal integrity and a decrease in performance. Hence, the cost-benefit analysis demonstrated that the use of this vaccine has a negative impact on company profits.

Supplementary Materials: The following are available online at https:/ / www.mdpi.com/article/10 $.3390 /$ vaccines $9080817 / \mathrm{s} 1$ : Table S1. Ingredient composition $(\mathrm{kg})$ and nutrient content of the phases of feed supplied to the experimental female broiler chickens. Table S2. Feeding phase costs and cost breakdown of experimental female broilers.

Author Contributions: Conceptualization, V.M.P.-G. and G.T.-I.; investigation and methodology, V.M.P.-G., V.M.V.-N. and M.D.-G.; formal analysis and software, V.M.P.-G., J.G.-S. and I.C.-H.; histopathology analysis, V.M.P.-G.; cost-benefit calculation, V.M.V.-N.; supervision, R.L.-A., F.A.-H. and G.T.-I.; validation and visualization, R.L.-A. and F.A.-H.; writing-original draft, V.M.P.-G. and G.T.-I.; writing-review and editing, R.L.-A., X.H.-V., F.A.-H. and G.T.-I. All authors read and agreed to the published version of the manuscript. 
Funding: This research obtained funding from the PAPIIT IT201620 project of DGAPA-UNAM, Universidad Nacional Autónoma de Mexico. The authors thank CONACyT for doctoral grant number 494367. This research was also partly supported by funds provided by the USDA-NIFA, Sustainable Agriculture Systems, Grant No. 2019-69012-29905; title of project: Empowering US Broiler Production for Transformation and Sustainability USDA-NIFA (Sustainable Agriculture Systems), No. 2019-69012-29905.

Institutional Review Board Statement: This study was conducted according to the guidelines of the Declaration of Helsinki and approved by the Internal Committee for Care and Use of Experimental Animals (CICUAE) of the National Autonomous University of Mexico (UNAM); ethical approval code: CICUAE-FESC C20_06.

Informed Consent Statement: Not applicable.

Data Availability Statement: Not applicable.

Conflicts of Interest: The authors declare no conflict of interest.

\section{References}

1. Pitcovski, J.; Goyal, S.M. Avian Reovirus Infections. In Diseases of Poultry; Swayne, D.E., Ed.; Wiley-Blackwell: Hoboken, NJ, USA, 2020; pp. 382-400. ISBN 978-1-119-37115-1.

2. Cebra, J.J.; Cebra-Thomas, J.A.; Cuff, C.F.; George, A.; Kost, S.I.; London, S.D.; Rubin, A.D.H. Immunology and Immunopathology of the Intestines: Reoviruses as Probes of the Gut Mucosal T Cell Population. Immunol. Investig. 1989, 18, 545-558. [CrossRef]

3. Jones, R.C. Avian Reovirus Infections. Rev. Sci. Tech. OIE 2000, 19, 614-625. [CrossRef]

4. Clark, F.D.; Ni, Y.; Collisson, E.W.; Kemp, M.C. Characterization of Avian Reovirus Strain-Specific Polymorphisms. Avian Dis. 1990, 34, 304. [CrossRef]

5. Jones, R.C.; Kibenge, F.S.B. Reovirus-induced Tenosynovitis in Chickens: The Effect of Breed. Avian Pathol. 1984, 13, 511-528. [CrossRef]

6. Jones, R.C.; Georgiou, K. Reovirus-induced Tenosynovitis in Chickens the Influence of Age at Infection. Avian Pathol. 1984, 13, 441-457. [CrossRef] [PubMed]

7. Dandár, E.; Bálint, Á.; Kecskeméti, S.; Szentpáli-Gavallér, K.; Kisfali, P.; Melegh, B.; Farkas, S.L.; Bányai, K. Detection and Characterization of a Divergent Avian Reovirus Strain from a Broiler Chicken with Central Nervous System Disease. Arch. Virol. 2013, 158, 2583-2588. [CrossRef]

8. van der Heide, L. The History of Avian Reovirus. Avian Dis. 2000, 44, 638. [CrossRef] [PubMed]

9. Hieronymus, D.R.K.; Villegas, P.; Kleven, S.H. Identification and Serological Differentiation of Several Reovirus Strains Isolated from Chickens with Suspected Malabsorption Syndrome. Avian Dis. 1983, 27, 246. [CrossRef]

10. van der Heide, L.; Kalbac, M.; Hall, W.C. Infectious Tenosynovitis (Viral Arthritis): Influence of Maternal Antibodies on the Development of Tenosynovitis Lesions after Experimental Infection by Day-Old Chickens with Tenosynovitis Virus. Avian Dis. 1976, 20, 641. [CrossRef] [PubMed]

11. Jones, R.C.; Islam, M.R.; Kelly, D.F. Early Pathogenesis of Experimental Reovirus Infection in Chickens. Avian Pathol. 1989, 18, 239-253. [CrossRef]

12. Rosenberger, J.K.; Sterner, F.J.; Botts, S.; Lee, K.P.; Margolin, A. In Vitro and in Vivo Characterization of Avian Reoviruses. I. Pathogenicity and Antigenic Relatedness of Several Avian Reovirus Isolates. Avian Dis. 1989, 33, 535. [CrossRef] [PubMed]

13. Zhong, L.; Gao, L.; Liu, Y.; Li, K.; Wang, M.; Qi, X.; Gao, Y.; Wang, X. Genetic and Pathogenic Characterisation of 11 Avian Reovirus Isolates from Northern China Suggests Continued Evolution of Virulence. Sci. Rep. 2016, 6, 35271. [CrossRef] [PubMed]

14. Giambrone, J.J.; Hathcock, T.L.; Lockaby, S.B. Effect of a Live Reovirus Vaccine on Reproductive Performance of Broiler Breeder Hens and Development of Viral Tenosynovitis in Progeny. Avian Dis. 1991, 35, 380. [CrossRef] [PubMed]

15. Kibenge, F.S.B.; Jones, R.C.; Savage, C.E. Effects of Experimental Immunosuppression on Reovirus-induced Tenosynovitis in Light-hybrid Chickens. Avian Pathol. 1987, 16, 73-92. [CrossRef] [PubMed]

16. Hill, J.E.; Rowland, G.N.; Latimer, K.S.; Brown, J. Effects of Cyclosporine A on Reovirus-Infected Broilers. Avian Dis. 1989, $33,86$. [CrossRef]

17. Songserm, T.; van Roozelaar, D.; Kant, A.; Pol, J.; Pijpers, A. Agnes ter Huurne Enteropathogenicity of Dutch and German Avian Reoviruses in SPF White Leghorn Chickens and Broilers. Vet. Res. 2003, 34, 285-295. [CrossRef]

18. Ross Broiler: Nutrition Specifications; Aviagen: Huntsville, AL, USA, 2019.

19. Ross Broiler Management Handbook; Aviagen: Huntsville, AL, USA, 2018.

20. Enterovax®. Available online: https://www.merck-animal-health-usa.com/product/enterovax (accessed on 18 March 2021).

21. Union Nacional de Avicultores (UNA). Compendio de Indicadores Económicos del Sector Avícola 2020; UNA: Ciudad de Mexico, Mexico, 2020.

22. Winston, W.L.; Goldberg, J.B. Operations Research: Applications and Algorithms, 4th ed.; Thomson/Brooks/Cole: Belmont, CA, USA, 2004; ISBN 978-0-534-38058-8. 
23. Liu, H.J.; Kuo, L.C.; Hu, Y.C.; Liao, M.H.; Lien, Y.Y. Development of an ELISA for Detection of Antibodies to Avian Reovirus in Chickens. J. Virol. Methods 2002, 102, 129-138. [CrossRef]

24. Rekik, M.R.; Silim, A.; Bernier, G. Serological and Pathogenic Characterization of Avian Reoviruses Isolated in Quebec. Avian Pathol. 1991, 20, 607-617. [CrossRef]

25. Denbow, D.M. Gastrointestinal Anatomy and Physiology. In Sturkie's Avian Physiology; Scanes, C.G., Ed.; Elsevier/Academic Press: London, UK, 2015; pp. 337-366. ISBN 978-0-12-407160-5.

26. Brown, J.J.; Short, S.P.; Stencel-Baerenwald, J.; Urbanek, K.; Pruijssers, A.J.; McAllister, N.; Ikizler, M.; Taylor, G.; Aravamudhan, P.; Khomandiak, S.; et al. Reovirus-Induced Apoptosis in the Intestine Limits Establishment of Enteric Infection. J. Virol. 2018, 92. [CrossRef]

27. Fletcher, O.J.; Abdul-Aziz, T. Alimentary System. In Avian Histopathology; Abdul-Aziz, T., Fletcher, O.J., Barnes, H.J., Eds.; AAAP, Inc.: Jacksonville, FL, USA, 2016; pp. 271-354.

28. Norris, T. Porth's Essentials of Pathophysiology, 5th ed.; Wolters Kluwer: Philadelphia, PA, USA, 2020; ISBN 978-1-975107-20-8.

29. Levin, R.J. Absorption from the alimentary tract. In Physiology and Biochemistry of the Domestic Fowl; Freeman, B.M., Bell, D.J., Freeman, B.M., Eds.; Academic Press: London, UK, 1984; Volume 5, pp. 1-21. ISBN 978-0-12-267105-0.

30. Davis, J.F.; Kulkarni, A.; Fletcher, O. Reovirus Infections in Young Broiler Chickens. Avian Dis. 2013, 57, 321-325. [CrossRef]

31. Xu, J.; Wang, L.; Tang, J.; Jia, G.; Liu, G.; Chen, X.; Cai, J.; Shang, H.; Zhao, H. Pancreatic Atrophy Caused by Dietary Selenium Deficiency Induces Hypoinsulinemic Hyperglycemia via Global Down-Regulation of Selenoprotein Encoding Genes in Broilers. PLoS ONE 2017, 12, e0182079. [CrossRef] [PubMed]

32. Scott, M.L.; Nesheim, M.C.; Young, R.J. Nutrition of the Chicken; M.L. Scott: Ithaca, NY, USA, 1982; ISBN 978-0-9602726-2-4.

33. Abdul-Aziz, T.; Fletcher, O.J. Endocrine System. In Avian Histopathology; Abdul-Aziz, T., Fletcher, O.J., Barnes, H.J., Eds.; AAAP, Inc.: Jacksonville, FL, USA, 2016; pp. 545-580.

34. Randall, C.; Wyeth, P.; Higgins, R. Pancreatic Lesions in Stunted Broilers. Vet. Rec. 1981, 109, 125-126. [CrossRef] [PubMed]

35. Whitacre, M.E.; Combs, G.F.; Combs, S.B.; Parker, R.S. Influence of Dietary Vitamin E on Nutritional Pancreatic Atrophy in Selenium-Deficient Chicks. J. Nutr. 1987, 117, 460-467. [CrossRef] [PubMed] 